\title{
PERCEPÇÃO AMBIENTAL DAS ARTESÃS QUE USAM AS FOLHAS DE CARNAÚBA (COPER- NICIA PRUNIFERA H.E.MOORE, ARECACEAE) NA ÁREA DE PROTEÇÃO AMBIENTAL DEL- TA DO PARNAÍBA, PIAUÍ, BRASIL
}

\section{Environmental perception of the artisans that work with leaves of carnauba palm (Copernicia prunif- era H.E.Moore, Arecaceae) in Delta do Parnaíba Environmental Protection Area, Piauí, Brazil}

\author{
Irlaine Rodrigues Vieira \\ Universidade Federal do Ceará, Fortaleza, Ceará, Brasil. \\ irlaine.vieira@yahoo.com.br \\ Maria Iracema Bezerra Loiola \\ Universidade Federal do Ceará, Fortaleza, Ceará, Brasil. \\ iloiola@ufc.br
}

Artigo recebido em 06/11/2012 e aceito para publicação em 04/09/2013

RESUMO: $\quad$ Este estudo investigou os aspectos socioeconômicos e a percepção ambiental das artesãs que subsistem da confecção de artesanato de folhas de carnaúba na Área de Proteção Ambiental Delta do Parnaíba, município de Parnaíba, Piauí. Foram entrevistadas 36 artesãs, pertencentes às comunidades Fazendinha, Vazantinha e Pedra do Sal, utilizando-se questionários semiestruturados. Paralelamente, o manejo das plantas foi acompanhado. O artesanato é feito por mulheres com idade entre 20 e 60 anos e de baixa escolaridade. Estas moram em comunidades desprovidas de saneamento básico, escolas e saúde pública de qualidade. A percepção sobre a planta é atribuída às suas utilidades, aos danos causados a esta e a especulação imobiliária. As artesãs de Fazendinha e Vazantinha não expressaram uma consciência conservacionista, prevalecendo, a percepção capitalista; já na comunidade de Pedra do Sal, as artesãs promovem a conservação ambiental. Estas realizam protestos e procuram os órgãos ambientais, visando impedir a devastação dos carnaubais. Observou-se que embora as artesãs desenvolvam a mesma atividade, possuem percepções diferentes sobre o ambiente e ao recurso explorado. Especialmente na comunidade Fazendinha é necessária a promoção da educação ambiental, a fim de conciliar o extrativismo ao equilíbrio ecológico.

Palavras-chave: extrativismo, artesanato, conservação ambiental, nordeste do Brasil.

ABSTRACT: This study investigated the socioeconomic aspects and environmental perception of artisans that subsists making handicrafts of the leaves of carnauba palm (Copernicia prunifera H. E. Moore) in the Delta do Parnaíba Environmental Protection Area, located in Paranaíba municipality, Piauí state. We interviewed 36 artisans belonging to communities Fazendinha, Vazantinha and Pedra do Sal, using semi-structured questionnaires. In parallel, the plant management was followed. The crafts are made by women with age ranging from 20 to 60 years and low education. They live deprived of basic sanitation, schools and public health of quality. The perception about the plant is attributed to carnauba utilitarian features. In the three communities damage to plant involves estate speculation. The artisans of Fazendinha and Vazantinha did not express a conservationist conscience, prevailing capitalist perception. In the community of Pedra do Sal, the artisans promote an environmental conservation. They contact environmental agencies and protest against the devastation of carnauba forest. It was observed that although artisans share the same activity, they have different perceptions of the environment and resource explored. Especially in the Fazendinha community is necessary construction of environmental education to promote a sustainable extraction.

Keywords: extraction, handicraft, environmental conservation, northeast Brazil.

DOI: $10.1590 / 1982-451320140105$ 


\section{INTRODUÇÃO}

A implementação de Unidades de Conservação é uma estratégia política que visa à proteção dos ecossistemas naturais (BRASIL, 1981). Entretanto, é comum a desarmonia de populações residentes nestas áreas com o ambiente em que estão inseridas, o que geralmente compromete a conservação dos recursos naturais destes locais (MILANO, 2000).

A inclusão da perspectiva social na elaboração de planos de manejo em Unidades de Conservação permite compreender em que contexto os recursos naturais destas áreas estão sendo extraídos (NORDI, 1992). Para tanto, é essencial compreender o papel das populações tradicionais extrativistas, através da identificação e caracterização do perfil socioeconômico destes indivíduos, bem como incluir o que pensam e como percebem o recurso explorado, abrangendo desta forma, a percepção ambiental desses (JOHANNE, 1993; HOEFFEL et al., 2011).

Pesquisas envolvendo a percepção ambiental, além de possibilitar a compreensão da inter-relação homem e meio ambiente, permite elucidar as perspectivas e sentimentos em relação aos recursos usados, revelando seu relacionamento cognitivo, emocional e cultural com a atividade que exerce (ZAMPIERON et al., 2003). Estes dados esclarecem os valores que envolvem a continuação de uma atividade e dos efeitos decorrentes dessa, os quais possibilitam traçar estratégias precisas para sanar possíveis falhas em educação ambiental, um dos objetivos das políticas ambientais (BRASIL, 1981; STRANZ, 2002).

Uma atividade extrativista expressiva no nordeste brasileiro é a confecção de artesanato provindo da palha de carnaúba (Copernicia prunifera (Miller) H.E.Moore, pertencente à família botânica das Arecaceae), sendo esta atividade responsável pelo sustento de inúmeras famílias (BANCO DO NORDESTE, 2002).

No estado do Piauí, se destaca a cidade de Parnaíba, mais precisamente a área rural inserida na Ilha Grande de Santa Isabel, parte integrante da Área de Proteção Ambiental Delta do Parnaíba (APA Delta do Parnaíba), dotada de extensos e densos carnaubais. Nessa APA, residem populações tradicionais que utilizam, há várias gerações, a palha da carnaúba na confecção de diferentes peças de artesanato para embelezamento de suas moradias e, principalmente, para a comerciali- zação e sustento de suas famílias (VIEIRA; VEROLA; LOIOLA, 2011). No entanto, tem-se verificado que a crescente valorização de produtos sustentáveis conciliados com a expansão do turismo vem promovendo o crescimento desta atividade e, consequentemente, maior pressão aos recursos naturais desta APA.

Este trabalho objetivou levantar o perfil socioeconômico e cultural, bem como a percepção ambiental das artesãs residentes na Ilha Grande de Santa Isabel que dependem do extrativismo da carnaúba para a confecção do artesanato, visando contribuir para a elaboração de políticas ambientais e sociais que resguardem a conservação das populações silvestres de $C$. prunifera.

\section{ASPECTOS METODOLÓGICOS}

\section{Área de estudo}

A APA Delta do Parnaíba foi criada pelo Decreto Federal de 28 de agosto de 1996, visando proteger os deltas dos rios Ubatuba, Timonha e Parnaíba; melhorar a qualidade de vida das populações residentes por meio da orientação e disciplina das atividades econômicas locais; fomentar o turismo ecológico e a educação ambiental, além de preservar as culturas e as tradições locais (BRASIL, 1996).

A presente pesquisa foi realizada em três comunidades (Fazendinha, Vazantinha e Pedra do Sal) pertencentes à região não continental do município de Parnaíba, Piauí (Figura 1). Considerando um transecto Fazendinha dista $3 \mathrm{~km}$ de Vazantinha e esta última aproximadamente $12 \mathrm{~km}$ de Pedra do Sal. Estas comunidades se distanciam da zona urbana do município 3 , 4 e $12 \mathrm{~km}$, respectivamente. Segundo IBGE (2010), a área pertencente ao município de Parnaíba localizada na Ilha Grande de Santa Isabel possui 5028 habitantes, não havendo informações disponíveis sobre o número de habitantes em cada comunidade. A Ilha Grande de Santa Isabel é parte integrante da Área de Proteção Ambiental Delta do Parnaíba (APA Delta do Parnaíba), que abrange uma área de 313.809 hectares. Esta situa-se nos municípios de Araióres, Água Doce, Paulino Neves e Tutóia no estado do Maranhão; Chaval e Barroquinha no estado do Ceará; Luíz Correia, Ilha Grande, Cajueiro da Praia e Parnaíba no estado do Piauí e, nas águas jurisdicionais dos rios Parnaíba, Timonha e Ubatuba, além de $5 \mathrm{~km}$ de mar territorial. 
Figura 1. Mapa de localização do município de Parnaíba, Piauí, Brasil.

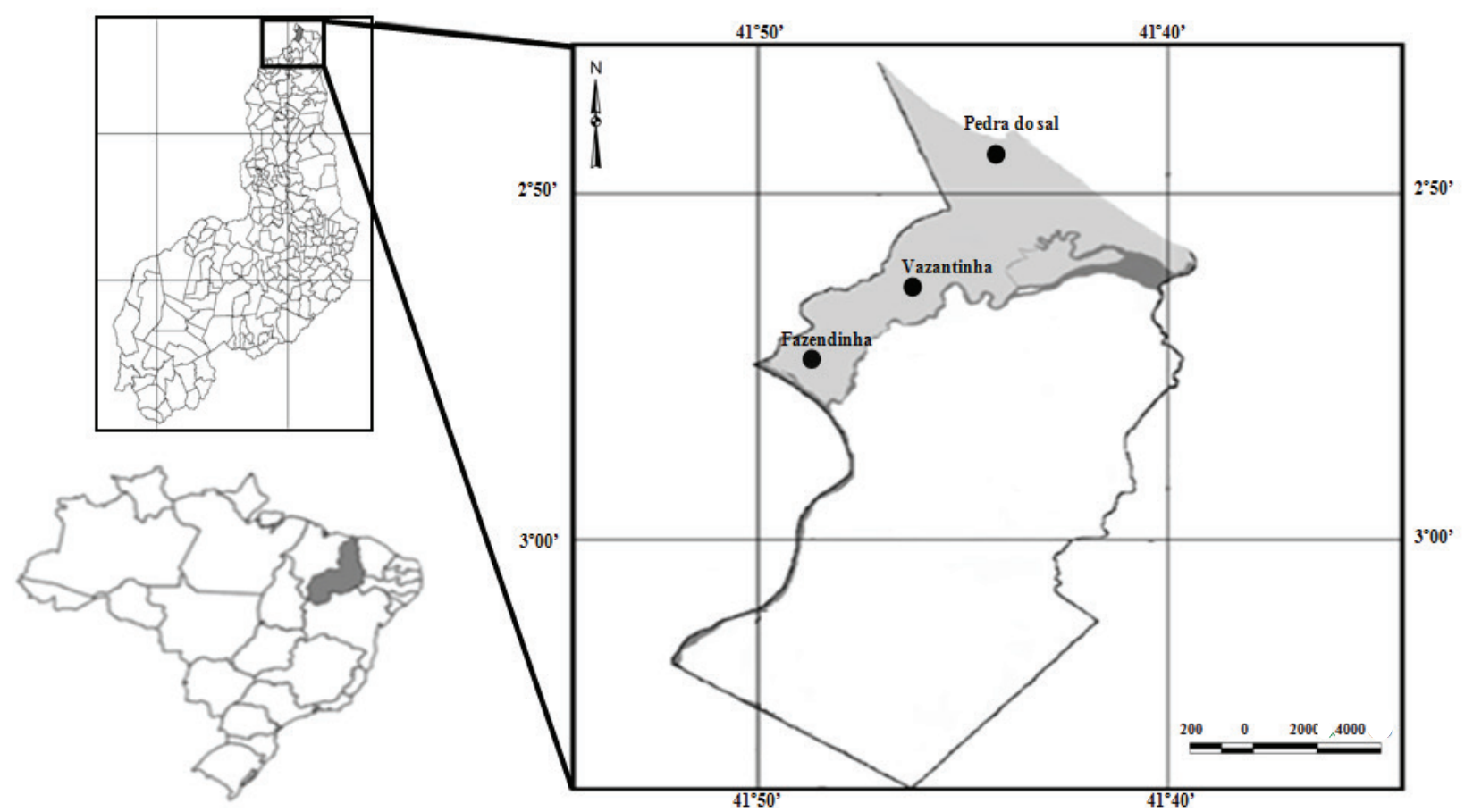

O mapa evidencia as comunidades de Fazendinha, Vazantinha e Pedra do Sal localizadas na porção não continetal do município, Ilha Grande de Santa Isabel (em cinza), região pertencente à Área de Proteção Ambiental Delta do Parnáiba.

Fonte: Adaptado de Ministério de Minas e Energias (2003). Org. das autoras.

O solo desta região é do tipo Planossolo (solo com alta atividade de argila, raramente profundos, apresentando problemas de encharcamento durante $o$ período chuvoso e ressecamento e fendilhamento durante a época seca; saturação com sódio (100.Na+/T) entre 6 e $15 \%$ nos horizontes Bt e/ou C, nos quais é elevado o teor de minerais decomponíveis) e o clima, segundo a classificação de Köppen, se enquadra como Aw', onde apresenta uma estação quente e chuvosa durante o verão e relativamente seca durante o inverno (JACOMINE et al., 1986; EMBRAPA, 1999). A fisionomia da vegetação é de restinga fruticetos inundáveis e não inundáveis, nucleados por espécies arbóreas, com formações de campos e extensos carnaubais (SANTOS FILHO, 2009).

A população de Fazendinha desenvolve o artesanato, a pesca, a agricultura de subsistência ou trabalham em serviços gerais no comércio de Parnaíba. Vazantinha compreende uma comunidade ribeirinha ao rio Igaraçu, principal rio do município, sendo composta principalmente por caiçaras. Além de desenvolver as mesmas atividades comerciais da comunidade de Fazendinha, seus habitantes trabalham em uma olaria instalada na região. A comunidade Pedra do Sal situa-se na porção norte da ilha, margeando a praia com o mesmo nome e, a população vive basicamente da pesca, da agricultura de subsistência, do artesanato e do comércio desenvolvido na praia, voltado aos turistas.

\section{Coleta e análise dos dados}

Foram realizadas viagens mensais no período de julho de 2011 a julho de 2012 à APA Delta do Parnaíba, com o intuito de localizar as associações de artesãs e de moradores e identificar as comunidades onde ocorre o extrativismo da carnaúba para a produção do artesanato.

Neste período foram identificados e entrevistados integrantes de associações de artesãos. Foram selecionadas três comunidades atreladas à confecção do artesanato e possuidoras de associações que agreguem principalmente artesãs.

Na comunidade de Fazendinha, as pessoas 
que fazem artesanato são do gênero feminino e se concentram em uma associação que trabalham exclusivamente com as folhas da carnaúba. Nesta associação houve a especialização da confecção do artesanato, de tal forma que dos 25 associados, 16 são mulheres e exclusivamente confeccionam o artesanato, enquanto os demais são homens que unicamente extraem as folhas e abastecem a produção. As artesãs de Vazantinha e Pedra do Sal pertencem à associação de moradores e são elas mesmas que extraem as folhas para a confecção do artesanato. A associação de moradores de Vazantinha possui 60 artesãos e destes, 15 artesãs trabalham com as folhas de carnaúba. Já na comunidade de Pedra do Sal, a associação de moradores possui 15 artesãs associadas, das quais cinco trabalham com a carnaúba. As demais fazem trabalhos com outras plantas como o coco (Cocos nucifera L., Areacaceae), o buriti (Mauritia flexuosa L.f., Arecaceae), o olho de boi ( Dioclea violacea Mart., Leguminosae), papel, areia ou bordados.

No total, 36 artesãs que trabalham unicamente com a carnaúba foram entrevistadas, assim distribuídas: Fazendinha (16), Vazantinha (15) e Pedra do Sal (5). O questionário foi direcionado em perguntas relacionadas ao perfil socioeconômico (idade, nível de renda, condições de moradia, escolaridade, entre outros) e ao levantamento da percepção ambiental das artesãs. Nesta etapa, foram realizadas perguntas abertas sobre a relação que elas tinham com a planta, a importância do vegetal para a sua sobrevivênvia, além de outras questões de cunho ambiental, referentes à conservação.

Foi ainda acompanhada a rotina nas comunidades quanto à extração das folhas e a confecção do artesanato, com o intuito de reforçar as repostas fornecidas, e assim rever a precisão das respostas, a partir do comportamento das atividades das artesãs extrativistas e dos coletores de palha.

Segundo Minayo (1993), a pesquisa qualitativa aborda o universo de crenças, atitudes, valores, motivos e significados, visando compreender as inter-relações que caracterizam a realidade, os quais não devem ser reduzidos a variáveis. Diante disso, e considerando que a compreensão da percepção se trata de um estudo de natureza social, histórico e cultural, não direcionado a quantificação, optou-se pela analise qualitativa.

\section{RESULTADOS E DISCUSSÃO}

As 36 artesãs entrevistadas são originárias da própria ilha onde residem. Estas edificam suas casas no interior dos carnaubais, de onde é explorado o recurso necessário para a produção do artesanato. Apesar das famílias dessas mulheres ocuparem a região há muito tempo, não possuem o registro legal de propriedade privada individual da terra. De acordo com Arruda (1999), é comum a ausência do registro legal de propriedade privada individual por parte de populações tradicionais residentes em unidades de conservação ambiental. Ainda segundo esse mesmo autor, estas definem o local de moradia como a parcela individual e as áreas não ocupadas como de utilização comunitária.

Nas comunidades de Fazendinha e Vazantinha mais de $50 \%$ das artesãs residem em casas de tijolos com cobertura de telhas de cerâmica (Tabela 1). Já em Pedra do Sal, a maioria mora em casas com paredes de tijolos e a cobertura da casa é feita com folhas de carnaúba (Figura 2). Quando questionadas o porquê desse tipo de cobertura, as artesãs foram unânimes em afirmar que foi uma opção para manter ou resgatar as raízes culturais.

Soc. \& Nat., Uberlândia, 26 (1): 63-76, jan/abr/2014 
Percepção ambiental das artesãs que usam as folhas de carnaúba (Copernicia prunifera H.E.Moore, Arecaceae) na Área de Proteção

Ambiental Delta do Parnaíba, Piauí, Brasil

Irlaine Rodrigues Vieira, Maria Iracema Bezerra Loiola

Tabela 1 - Tipo de construção/moradia encontrada nas comunidades Fazendinha, Vazantinha e Pedra do Sal em Ilha Grande de Santa Isabel, Parnaíba, Piauí.

\begin{tabular}{|c|c|c|c|}
\hline Tipo de construção/moradia & \multicolumn{3}{|c|}{ Frequência das respostas por comunidade (\%) } \\
\hline & Fazendinha & Vazantinha & Pedra do Sal \\
\hline Casa de tijolo, cobertura de telha & 75 & 60 & 25 \\
\hline Casa de tijolo, cobertura de palha & 0 & 0 & 50 \\
\hline Taipa, cobertura de telha & 25 & 20 & 0 \\
\hline Taipa, cobertura de palha & 0 & 20 & 25 \\
\hline
\end{tabular}

Fonte: Pesquisa direta, 2011.

Destaca-se que além da cobertura de casas, a carnaúba é utilizada para edificar as paredes de residências de $25 \%$ das artesãs na comunidade Fazendinha, $40 \%$ em Vazantinha e $25 \%$ em Pedra do Sal. Estas moradias, localmente denominadas de "taipa", são feitas a partir de uma trama de pecíolo e ripas do tronco, formando-se uma placa que recebe uma mistura de barro e água, edificando as paredes da casa (Figura 3). Isto revela que, além de fonte de renda na produção de artesanato, a carnaúba é provedora de outras utilidades estando entrelaçada ao modo de vida destas comunidades, reforçando a presença desta espécie na cultura deste povo. Por outro lado, o fato da maioria das casas serem de alvenaria (de tijolos e telhas) reflete uma opção das artesãs diante da durabilidade destes e de melhoras na renda familiar. De um modo geral, foi observado que a falta de recursos financeiros motivam a utilização da planta, à exceção da comunidade de Pedra do Sal que a utiliza para manutenção de valores culturais.

Figura 2. Casa de tijolo, com cobertura de palha, Ilha Grande de Santa Isabel.

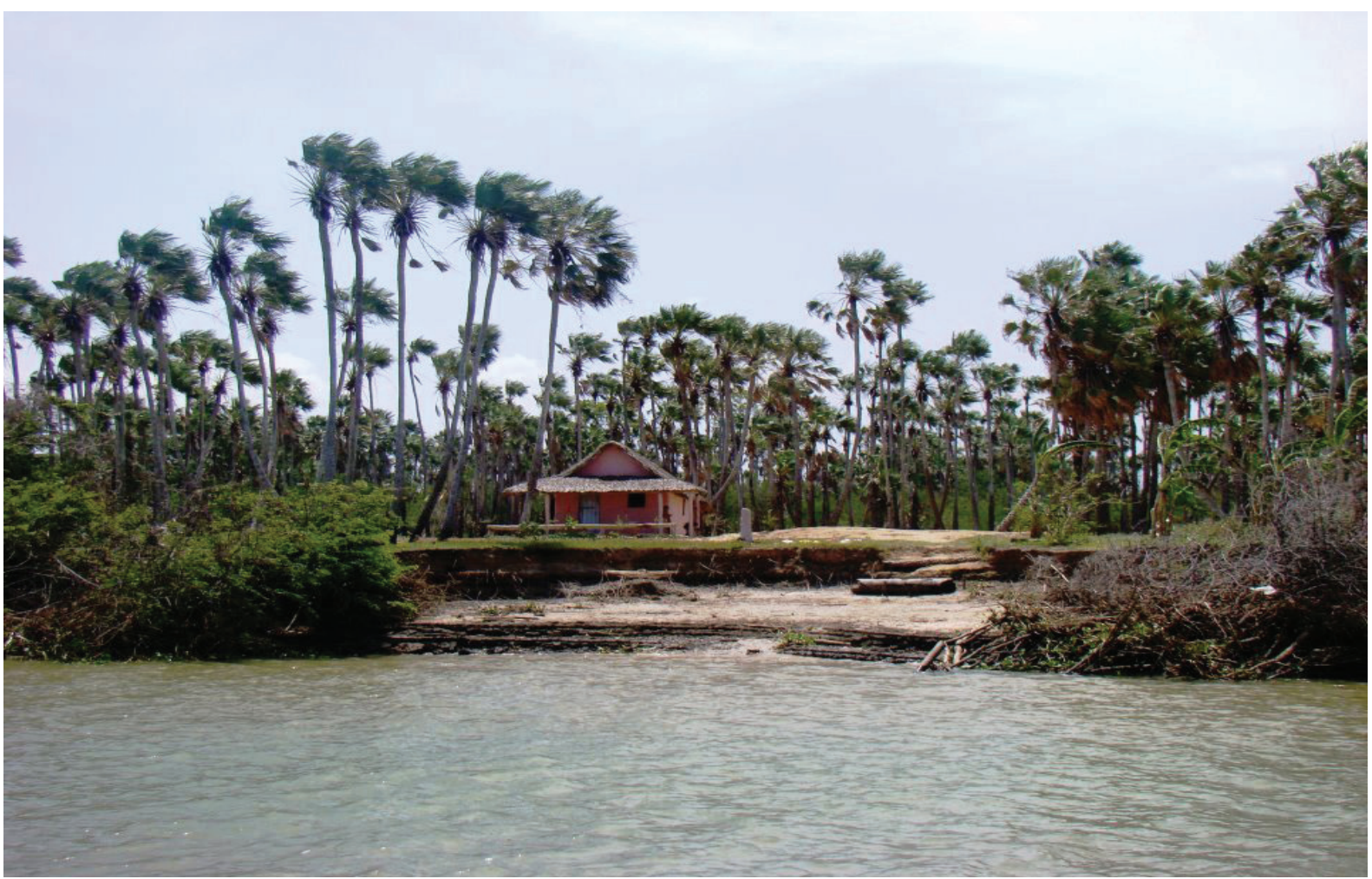

Fonte: Foto cedida por Morais Brito (s/d). 
Figura 3. Casa de taipa com cobertura de palha, Ilha Grande de Santa Isabel.

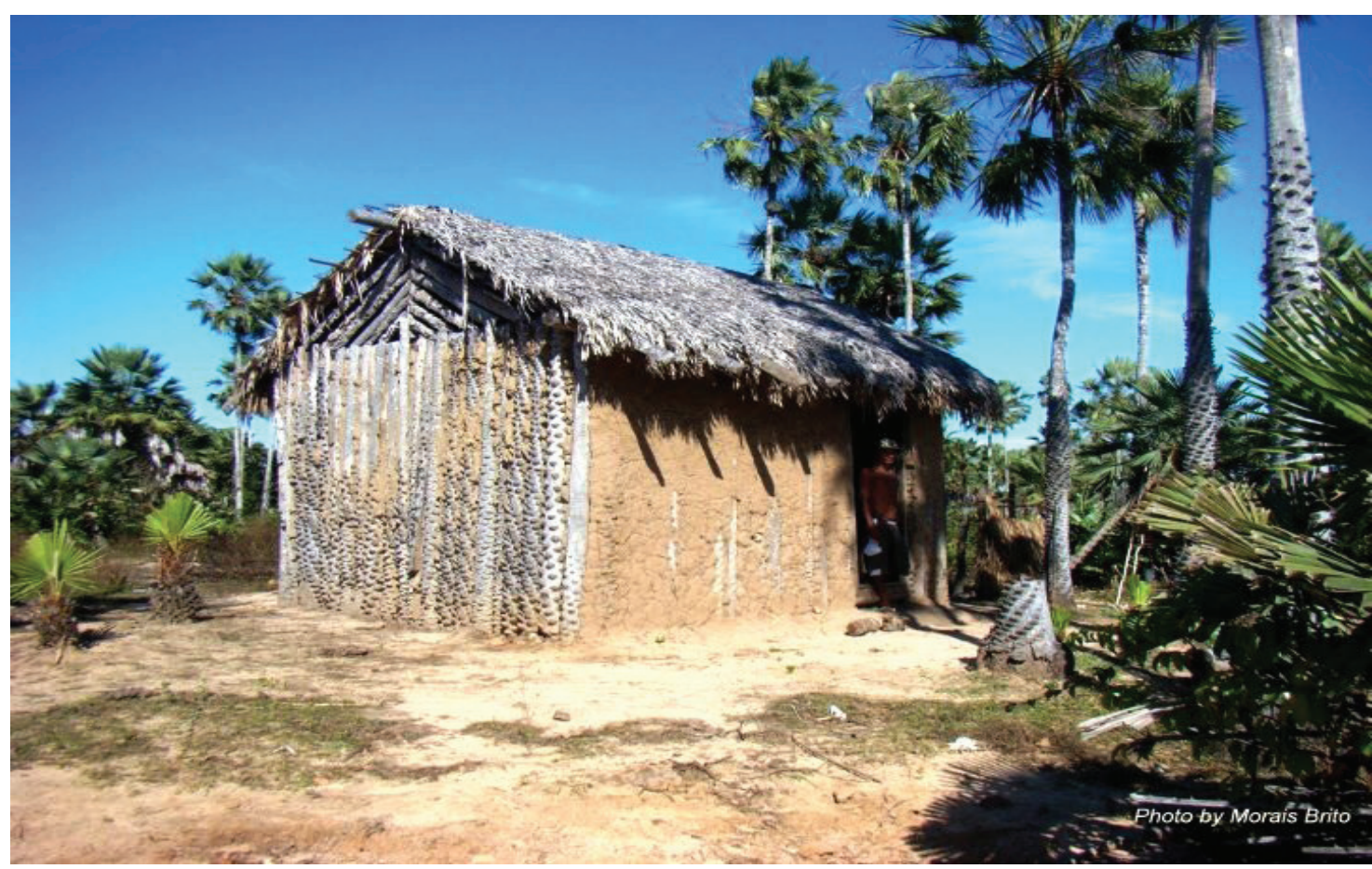

Fonte: Foto cedida por Morais Brito (s/d).

No estudo realizado por Santos (2007) no município de Tobias Barreto, em Sergipe, também foi verificada a maior proporção de casa de alvenaria entre os artesãos, sendo que apenas 3\% destes residiam em casa de taipa. Esse autor constatou ainda que a moradia de taipa esta relacionada a uma insipiente condição financeira.

A respeito do acesso aos serviços públicos prestados pelo governo municipal foi constatado que nas três comunidades todas as artesãs têm acesso e utilizam a energia elétrica. Em relação ao uso de água tratada, verificou-se que fazem uso desta $93,75 \%$ na comunidade de Fazendinha; 100\% em Vazantinha, uma vez que há na localidade um chafariz público e, em Pedra do Sal, apenas 50\% tem acesso a esse serviço. As três comunidades também dispõem de coleta pública de lixo; entretanto, $12,5 \%$ dos entrevistados de Fazendinha e $50 \%$ dos entrevistados da Pedra do Sal preferem queimar e enterrar os resíduos sólidos.

Embora as comunidades sejam beneficiadas com programas de água tratada e coleta de lixo, nenhuma delas possui rede coletora de esgoto sanitário. Aproximadamente $18,5 \%$ das residências das entrevistadas em Fazendinha e $80 \%$ em Vazantinha não possuem instalações sanitárias e liberam os resíduos nas ruas. As residências das artesãs de Pedra do Sal possuem um sistema de encanamento que despeja os efluentes em uma caixa de concreto sem fundo. $\mathrm{Ou}$ seja, o esgoto é depositado diretamente no solo, contribuindo para a poluição deste e dos recursos hídricos.

No que diz respeito ao acesso à saúde, os moradores da Fazendinha e Vazantinha compartilham o mesmo posto de saúde e Pedra do Sal possui um posto próprio. Estes postos possuem serviços ambulatoriais básicos e fornecem medicamentos à população. Em Fazendinha há apenas escola de Ensino Fundamental e para quem desejar cursar o ensino médio e superior, a prefeitura disponibiliza transporte para que estes se desloquem até o centro da cidade de Parnaíba, ocorrendo o mesmo com a comunidade Pedra do Sal. A comunidade de Vazantinha não possui escola, apenas uma creche. Para ter algum nível de instrução, os moradores desta comunidade também precisam se deslocar até o centro comercial da cidade de Parnaíba.

Considerando a idade, as artesãs da comunidade de Fazendinha têm entre 22 e 56 anos (média $=37 \pm$ 9,23 anos), sendo que a artesã com mais experiência trabalha há 35 anos e a com menor experiência há nove anos (média $=20 \pm 7,65$ anos). Em Vazantinha, a idade 
das artesãs variou entre 20 a 60 anos de idade (média= $38 \pm 4,5$ anos), e o tempo de exercício da profissão entre seis e 55 anos (média $=31.6 \pm 4.32$ anos). Já na comunidade Pedra do Sal, a idade delas variou entre 31 e 52 anos (média $=39 \pm 9.5$ anos), e trabalhando de 24 a 49 anos (média $=33 \pm 11$ anos).

Quanto à escolaridade, a maioria possui ensino fundamental incompleto (Tabela 2). A causa dessa baixa escolaridade é atribuída à falta de escolas na região e a necessidade de auxiliar na renda doméstica quando estas ainda eram adolescentes. Segundo Freitas (2006), é comum a baixa escolaridade entre os artesãos, sendo esta uma das principais causas destes recorrerem ao artesanato como fonte de renda.

Nas comunidades de Vazantinha e Pedra do Sal, $100 \%$ das artesãs entrevistadas aprenderam a fazer o artesanato com as mães. Diferentemente em Fazendinha, uma parcela considerável das artesãs aprendeu a confeccionar o artesanato com outros parentes (25\%) e vizinhos $(18,75 \%)$.
Para alguns autores (SCHMIDT et al., 2007; DINIZ; DINIZ, 2007), o fato da mãe passar sua arte para a(s) filha(s) é uma característica do fazer artesanal cultural, onde o vínculo entre os indivíduos fazem com que a tradição da família seja seguida, sendo a mãe a principal transmissora da cultura. Em relação à Fazendinha, merece destacar que esta comunidade recebe grandes quantidades de encomendas para abastecimento local, nacional e até internacional. Isso pode despertar o interesse dos moradores para aprender a produzir o artesanato sendo este, provavelmente, o principal motivo desta diferença observada. Este fato corrobora a observação feita por Schmidt (2005), no qual a expansão comercial do artesanato provindo do capim dourado (Syngonanthus nitens (Bong.) Ruhland, Eriocaulaceae), na região do Jalapão, estado de Tocantins, fez com que os ensinamentos ultrapassassem os vínculos de parentesco e, além disso, englobasse também o gênero masculino.

Tabela 2 - Escolaridade das artesãs das comunidades de Fazendinha, Vazantinha e Pedra do Sal em Ilha Grande de Santa Isabel, Parnaíba, Piauí.

\begin{tabular}{|c|c|c|c|}
\hline Escolaridade & \multicolumn{3}{|c|}{ Frequência das respostas nas comunidades (\%) } \\
\hline & Fazendinha & Vazantinha & Pedra do Sal \\
\hline Analfabeto & 0 & 10 & 0 \\
\hline Ensino fundamental incompleto & 62,5 & 50 & 50 \\
\hline Ensino fundamental completo & 25 & 0 & 0 \\
\hline Ensino médio incompleto & 0 & 30 & 25 \\
\hline Ensino médio completo & 12,5 & 10 & 0 \\
\hline Ensino superior & 0 & 0 & 25 \\
\hline
\end{tabular}

Fonte: Pesquisa direta, 2011. Org. das autoras.

Sabe-se que a comercialização de produtos confeccionados com fibras naturais vem ganhando força pela valorização dos produtos sustentáveis e étnicos, conciliados a expansão do turismo (ALEXÍADES; SHANLEY, 2004). Aliados a essa conjuntura, o crédito governamental, o apoio de órgãos como SEBRAE, a constante requalificação, e a exposição em feiras nacionais fazem com que a atividade envolva, a cada dia, mais moradores locais. As 16 artesãs vinculadas à associação de Fazendinha não seriam capazes de produzir todo o artesanato encomendado, assim, ensinam a suas vizinhas para que com o trabalho coletivo possam atender a demanda dentro do prazo. Por conta do grande número de encomendas, as mulheres de Fazendinha passaram a trabalhar até 11 horas por dia. $\mathrm{O}$ artesanato é produzido principalmente durante a noite, enquanto no período diurno cuidam dos filhos e dos afazeres domésticos. Diante da falta de tempo, o extrativismo das folhas passou a ser realizado pelos maridos, filhos ou parentes. Ainda há aquelas que compram as folhas, pagando seis reais por 100 unidades. Na comunidade de Vazantinha e Pedra do 
Sal são as próprias artesãs que extraem as folhas com auxílio de uma foice ou faca, dependendo da altura da planta, trabalhando por 3 a 4 horas por dia.

Na comunidade de Vazantinha os produtos são vendidos a atravessadores e apenas $20 \%$ das artesãs vendem seus produtos para a associação dos moradores. Já em Pedra do Sal, 90\% da produção são comercializadas na sede da associação e 10\% a atravessadores. Segundo SEBRAE (2012), vender diretamente aos consumidores finais permite uma maior arrecadação de lucros que aquela comercialização realizada por intermediários. Porém, a venda irregular dos produtos nas comunidades de Vazantinha e Pedra do Sal faz com que estes dependam de atravessadores e da presença de turistas.

Quando questionados quais os problemas para a comercialização, todas as comunidades destacaram principalmente o baixo valor comercial das peças. As artesãs de Fazendinha, que estão mais bem estabelecidas comercialmente, relataram que encontram problemas também relacionados ao fornecimento de nota fiscal e a falta de meios de transporte para entregar a mercadoria. Em Vazantinha, o único problema destacado foi o baixo preço da venda; já na comunidade de Pedra do Sal foi mencionada ainda a desvalorização local dos produtos, bem representado na citação: "O problema é que o povo daqui não valoriza, gosta mesmo é "das coisa industrializada". Eu, eu não. Pego o meu coifo e vou pro mercado. Não gosto de sacolas plásticas, elas poluem o ambiente" (Artesã, comunidade Pedra do Sal).

A falta de valorização da cultura artesanal de uma região pode ameaçar sua produção, fato registrado no trabalho de Sousa e Sousa (2007), na cidade de Taquaruçu, Tocantins. Neste local, a expansão urbana vem promovendo desvalorização do artesanato por parte dos moradores e pelos próprios artesãos, ocasionando a perda do conhecimento popular de técnicas artesanais e ameaçando de extinção o artesanato provindo de estruturas vegetativas do Buriti (Mauritia flexuosa Mart., Arecaceae). Por outro lado, Canclini (1984) e Ribeiro (1984) ressaltaram que os valores dos artesanatos geralmente são incompatíveis com o tempo e o esforço dispensado para se produzir as peças e que isso ocorre por que, em uma comunidade tradicional, o artesanato é produzido pelo seu valor de uso e vendido pelo seu valor de troca, entretanto o consumidor o compra pelo seu valor estético.

Considerando a participação do artesanato no trabalho e no sustento familiar das artesãs, verificou-se que em Fazendinha, das $3 \pm 1,98$ pessoas em idade economicamente ativa residentes em uma moradia, em média $2 \pm 2,09$ trabalham com artesanato. Destas, $6,25 \%$ retiram sua renda exclusivamente do artesanato, sendo esta suficiente para o sustento da família. Das famílias que possuem outra fonte de renda, $68,5 \%$ afirmaram que o artesanato é a principal fonte de renda, arrecadando em média mais de um salário mínimo por mês. A comercialização permitiu o acesso a serviços particulares, como escola e saúde; proporcionou melhores condições de moradia e a aquisição de vários bens de consumo que variam de aparelhos celulares a transporte privado. Além disso, as artesãs vêem na produção do artesanato a saída para o sustento de suas famílias: "Meu maior desgosto dessa vida é das minhas filhas não ter se interessado em aprender fazer o artesanato e tanto que eu tentei. Se elas trabalhassem nisso hoje elas tinham as coisas." (Artesã, comunidade Fazendinha).

Em Vazantinha, a produção do artesanato representa um ínfimo auxílio na renda familiar, sendo necessário que os integrantes das famílias recorram a outras fontes remunerativas e dependa de auxílio governamental como o Programa Bolsa Família. Nesta comunidade em média existem $3 \pm 0,84$ pessoas em idade economicamente ativa por residência e desta em média apenas $1 \pm 0,63$ pessoa trabalha com o artesanato, vendendo a intermediários e obtendo uma renda de menos de um salário mínimo. Percebe-se que nesta comunidade há ausência de um elo cultural e a insignificante renda faz com que as artesãs busquem outros meios para obter renda e distancie cada vez mais as artesãs do recurso explorado.

Já na comunidade de Pedra do Sal, 90\% das famílias das artesãs dependem unicamente dos recursos naturais para seu sustento. Nestas famílias existem em média, $3 \pm 1,5$ pessoas por residência em idade economicamente ativa, na qual pelo menos uma pessoa depende da carnaúba para a produção do artesanato e as demais da pesca. A renda principal das famílias provém da pesca e do seguro pesca, sendo a venda do artesanato um auxílio mensal de menos de um salário mínimo. Segundo o Ministério do Trabalho 
e Emprego (2012) este auxílio, também chamado de seguro defeso, corresponde a uma assistência financeira concedida a pescadores profissionais que exerçam a atividade artesanalmente e que teve suas atividades paralisadas no período de defeso.

Segundo estas artesãs a principal função da confecção do artesanato não é especificamente a renda, mas a necessidade intrínseca de manter a cultura. A confecção se constitui em uma terapia ocupacional, relaxante e gratificante: "Tudo na vida é com trabalho. Nós temos a necessidade de resgatar a nossa cultura, por um prazer pessoal, de fazer o que gosta. "(Artesã, comunidade Pedra do Sal).

Quando questionadas qual a importância da carnaúba, todas remeteram aos benefícios econômicos do extrativismo. Além dessa percepção, $10 \%$ das artesãs de Vazantinha incluíram o benefício estético que a planta desempenha na paisagem da ilha. Nas comunidades estudadas é possível verificar a predominância de uma visão antropocêntrica, que segundo Singer (1994) configura-se em uma concepção utilitarista do meio ambiente. A percepção paisagística também se enquadra em uma concepção antropocêntrica, uma vez que sua função é a configuração de um cenário relaxante, enfatizando a utilidade exclusivamente humana da planta, reflexo da predominância dos valores comerciais sobre os valores culturais incutidos nessas artesãs.

Avaliando que todas as entrevistadas consideraram que a carnaúba é de extrema importância para elas frente às utilidades, supõe-se que a planta seja protegida pelas artesãs e que tenham a consciência dos fatores humanos e ambientais que afetam negativamente o recurso utilizado. Diante disso, estas foram questionadas sobre os fatores que afetam negativamente a planta. As três comunidades relataram que o avanço imobiliário sobre os carnaubais tem promovido o desmatamento destes, prejudicando as populações de carnaúbas. Sendo que em Vazantinha este avanço é ocasionado pelos próprios moradores da comunidade, na edificação de suas residências. Apesar da olaria instalada nessa comunidade também promover a devastação de carnaúbas, esta não foi citada.

Na comunidade de Pedra do Sal, os problemas enfrentados com a especulação imobiliária são promovidos pela compra de terrenos destinados a futuros empreendimentos turísticos, os quais ameaçam o acesso a extensos carnaubais e a desapropriação e remoção das artesãs. Explicitado no relato: Aqui eu e os meus se criaram. Querem tirar a gente daqui. Daqui eu não saio e se eu sair vou viver de quê?" (Artesã, comunidade Pedra do Sal).

Além da especulação imobiliária foram citados outros fatores como prejudiciais às plantas (Tabela 3). Na comunidade Pedra do Sal remeteu-se que a exploração desenfreada das folhas para a extração da cera afeta negativamente a planta, pois segundo as artesãs, muitos extrativistas removem todas as folhas, flores e frutos e consequentemente comprometem o desenvolvimento da planta e, em alguns casos, promovem a morte desta. Outro dano seria o desmatamento promovido pela instalação da usina eólica, fato este gerador de conflitos nesta comunidade.

Tabela 3. Elementos e atitudes prejudiciais à carnaúba segundo a porcentagem de respostas das artesãs das comunidades de Fazendinha, Vazantinha e Pedra do Sal em Ilha Grande de Santa Isabel, Parnaíba, Piauí.

\begin{tabular}{|c|c|c|c|}
\hline Danos ocasionados a C. prunifera & \multicolumn{3}{|c|}{ Frequência de resposta por comunidade (\%) } \\
\hline & Fazendinha & Vazantinha & Pedra do Sal \\
\hline Desmatamento & 20 & 100 & 50 \\
\hline Remoção das folhas imaturas & 40 & & \\
\hline Predação de Lagartas & 20 & & \\
\hline Intensiva exploração & 20 & & 50 \\
\hline
\end{tabular}

Fonte: Pesquisa direta, 2012. Org. das autoras. 
Quando questionadas sobre os problemas relacionados às práticas de manejo, na comunidade de Fazendinha foi relatado que alguns extrativistas removem todas as folhas imaturas de uma planta, promovendo a morte desta. Citaram também que a crescente e intensa exploração das carnaúbas para a produção do artesanato vem reduzindo o número e o tamanho de folhas produzidas pelas plantas e, consequentemente, tem prejudicado o vigor destas. Também afirmaram que as carnaúbas da localidade já não suprem a demanda de folhas. Isto faz com que os moradores da comunidade de Fazendinha avancem para outras comunidades em busca do recurso.

Além deste fato, foi registrado em Fazendinha que durante a extração das folhas são removidas também as inflorescências e infrutescências das plantas exploradas. Esta prática evita que os frutos se desenvolvam e, por conseqüência afeta negativamente a germinação e estabelecimento de novos indivíduos, o que pode prejudicar a manutenção da espécie no local. Por outro lado, em Vazantinha e Pedra do Sal as práticas de manejo não afetam negativamente a planta, uma vez que as flores e frutos não são removidos durante a extração das folhas e; além disso, não exploram a mesma planta dentro de um prazo de um mês. Entretanto é verificada que a comunidade devasta o carnaubal para a construção de moradias. Além de práticas ambientalmente sustentáveis, as artesãs de Pedra do Sal organizam passeatas para protestar contra o desmatamento do carnaubal, e exigem a proteção dos recursos vegetais e a criação de uma reserva extrativista e por consequência, a manutenção de sua cultura. Estas também participam ativamente de reuniões públicas de órgãos ambientais, visando contribuir positivamente na gestão da APA.

De acordo com Hall e Bawa (1993) e Boot e Gullison (1995), os benefícios econômicos resultantes de uma atividade extrativista interferem diretamente nas práticas de manejo, uma vez que produtos florestais que alcançam valoração econômica e expansão comercial podem ter como consequência, à intensificação da exploração ultrapassando, desta forma, a capacidade de suporte de regeneração da espécie explorada.

No trabalho realizado por Botha e Shackleto, (2004) em Mpumalanga, África do Sul, observou que a valorização comercial da casca medicinal da planta
Warburgia Salutaris (Bertol.f.) Chiov. (Canellaceae) intensificou a exploração da planta e alterou as práticas de manejo, havendo a ocorrência de incêndios regulares e sendo a mesma planta repetidamente explorada dentro de um curto espaço de tempo afetando o desenvolvimento destas plantas.

Considerando a percepção ambiental das artesãs de Fazendinha, contatou-se que estas possuem a consciência que a intensa exploração das carnaúbas da comunidade interfere negativamente na produção de folhas na planta. Apesar de a planta ser a fonte de matéria prima para a confecção do artesanato e para a obtenção de renda, isso não é o bastante para incentivá-las a orientar seus maridos e familiares a realizarem intervalos de exploração ou poupar as flores e frutos das carnaúbas.

Percebe-se que em Fazendinha as leis sociais e econômicas submetidas às artesãs são mais significantes que as leis ecológicas. Provavelmente devido à influência do sistema econômico capitalista em que estes indivíduos estão inseridos. Além disso, a imprevisibilidade, sazonalidade e a incerteza das encomendas levam estas artesãs a atuarem em desarmonia com a natureza e com elas mesmas frente às massivas horas de trabalho.

Segundo Arruda (1999), danos ambientais promovidos por populações tradicionais residentes em unidades de conservação são frutos de um dilema entre manter os padrões usuais de reprodução sociocultural ou assimilar o comportamento de uma sociedade capitalista. Vale ressaltar que as comunidades de Vazantinha e Fazendinha estão localizadas a poucos quilômetros do centro comercial de Parnaíba (aproximadamente $3 \mathrm{~km}$ ) e, portanto, estão mais relacionadas com a rotina capitalista que a comunidade Pedra do Sal (distante $12 \mathrm{~km}$ ), onde a cultura conservacionista prevalece.

Quando questionadas sobre a existência da APA do Delta do Parnaíba, 90\% das entrevistadas da comunidade de Fazendinha não sabiam o que é e não sabiam que este é um lugar que deve ser cuidado. As demais (10\%) sabiam que ali era um local importante ambientalmente, porém não sabiam o porquê. Entretanto, levantaram a hipótese que seria por conta de ser um local frágil, que se modifica rapidamente se interferido pelo homem. Citaram também que poderia ser por causa da presença do caranguejo e da carnaúba. Cem por cento das entrevistadas da comunidade de Vazantinha disseram não saber o que significava. 
Na comunidade Pedra do Sal, as artesãs também não sabiam o significado de uma APA, entretanto, têm a consciência de que aquele local é uma área de relevante interesse ambiental em virtude da riqueza vegetal e animal, citando também a beleza do local. As artesãs desta comunidade frequentam as reuniões dos órgãos ambientais locais com a finalidade de compreender e interferir positivamente na conservação dos recursos da comunidade. Entretanto, afirmaram que suas opiniões e seus interesses são marginalizados dentro das tomadas de decisões da administração da APA.

De acordo com alguns autores, é comum que populações residentes em unidades de conservação desconheçam que residem em uma área de relevante interesse ambiental. Em um estudo desenvolvido por Dias; Rosa e Damasceno (2007) com marisqueiras da Reserva de Desenvolvimento Sustentável Ponta do Tubarão, Macau/Rio Grande do Norte, constatou que $37,5 \%$ das entrevistadas desconhecem que a área onde moram é uma reserva ambiental e $60 \%$ das que sabiam, foram incapazes de definir o que é, mas tinham noção da importância ambiental do local onde vivem. Segundo Arruda (1999), a ausência de conhecimento por parte de populações tradicionais se deve ao modelo de unidade de conservação adotado no Brasil, onde as autoridades estabelecem uma área e de que modo esta será submetida a um regime de proteção, sem que as pessoas que residem nestes locais sejam participadas das tomadas de decisão. Este mesmo autor afirmou que, as decisões geralmente são sigilosas, a fim de que a população local não venha tomar qualquer atitude que prejudique a transformação dessa decisão em lei e assim comprometam os gestores.

\section{CONCLUSÕES}

As artesãs possuem percepções diferentes, apesar de desenvolverem a mesma atividade produtiva, e se enquadrarem no mesmo gênero e local de moradia. Os indivíduos das comunidades de Fazendinha e Vazantinha percebem o ambiente em que moram como lugar provedor de moradia e matéria prima para a confecção do artesanato. Esta percepção reflete o modo como estas comunidades interagem com o meio e com o recurso explorado. Em Fazendinha a lucratividade do artesanato implica em um manejo inadequado e em Vazantinha o baixo lucro resulta na desvalorização da planta e consequentemente na ausência de proteção desta. Já as artesãs de Pedra do Sal compreendem a importância da APA e contribuem positivamente para a proteção dos recursos naturais. Nesta comunidade a produção artesanal ultrapassa a obtenção de renda e fundamenta-se na necessidade de manter a tradição.

Esta divergência de percepções entre as comunidades está atrelada principalmente aos valores incutidos em cada comunidade, sejam eles capitalistas ou culturais e, além destes a presença ou ausência da compreensão da importância ambiental do local onde vivem. As artesãs de Fazendinha e Vazantinha desconhecem a relevância ecológica do local onde vivem e a não participação da gestão da APA, aliada à falta de oportunidades de obtenção de renda e consciência conservacionista fazem com que os recursos naturais destas comunidades sejam explorados irracionalmente. Na comunidade Pedra do Sal a participação ativa em reuniões de órgãos ambientais, possibilita o conhecimento político/ambiental da área onde moram e isto, associado aos laços estreitos com a cultura resultam na manutenção do carnaubal na comunidade. Estas artesãs participam ativamente da gestão da APA por meio de reuniões realizadas pelo órgão ambiental responsável pela administração da unidade de conservação.

Portanto, nas comunidades de Vazantinha e, principalmente em Fazendinha, há a necessidade da inclusão dos artesãos e extrativistas na gestão territorial por parte do órgão gestor da APA, a fim de promoverem nestes a conscientização e a educação ambiental. Essa estratégia os orientaria quanto à importância do local, a práticas saudáveis de saneamento e a atitudes que permitam a harmonia entre o extrativismo e o equilíbrio ecológico. Para a comunidade Pedra do Sal é necessário que o órgão gestor possibilite a reprodução da cultura conservacionista, evitando a devastação das carnaúbas e remoção das artesãs frente à especulação imobiliária.

Em todas as comunidades é necessário que a prefeitura do município instale um sistema coletor sanitário e um abastecimento hídrico eficiente para a promoção de uma melhor qualidade de vida para os moradores e, para a manutenção do equilíbrio ecológico na Área de Proteção ambiental Delta do Parnaíba. 
Percepção ambiental das artesãs que usam as folhas de carnaúba (Copernicia prunifera H.E.Moore, Arecaceae) na Área de Proteção Ambiental Delta do Parnaíba, Piauí, Brasil

Irlaine Rodrigues Vieira, Maria Iracema Bezerra Loiola

\section{AGRADECIMENTOS}

As autoras agradecem à FUNCAP, pelo auxílio financeiro para a realização da pesquisa.

\section{REFERÊNCIAS}

ALEXÍADES, M. N.; SHANLEY, P. Productos forestales, medios de subsistencia y conservación: estudios decaso sobre sistemas de manejo de productos forestales no maderables. Jakarta: CIFOR, 2004.

ARRUDA R. "Populações tradicionais" e a proteção dos recursos naturais em unidades de conservação. Ambiente \& Sociedade, São Paulo, v. 2, n. 5, p.79-92, jul./dez. 1999.

BANCO DO NORDESTE. Ações Para o Desenvolvimento do Artesanato do Nordeste- Estado do Ceará. 2 ed. Fortaleza: Banco do Nordeste. 2002.

BOOT, R. G. A.; GULLISON, R. E. Approaches to developing sustainable extraction systems for tropical forest products. Ecological Applications, London, v. 5, n. 4, p. 896-903, nov. 1995.

BOTHA, J.; WITKOWSKI, E. T. F.; SHACKLETON, C. M. The impact of commercial harvesting on Warburgia salutaris ('pepper-bark tree') in Mpumalanga, South Africa. Biodiversity and Conservation, Netherlands, v. 13, n. 9, p. 1675-1698, ago. 2004.

BRASIL. Lei No 6.938, de 31 de agosto de 1981. Dispõe sobre a Política Nacional do Meio Ambiente, seus fins e mecanismos de formulação e aplicação, e dá outras providências. Diário oficial da república federativa do Brasil. Brasília, DF, 31 ago. 1981.

BRASIL. Decreto n 99.274, de 6 de junho de 1990. Dispõe sobre a criação da Área de Proteção Ambiental Delta do Parnaíba, nos Estados do Piauí, Maranhão, e Ceará, e dá outras providências. Diário Oficial da República Federativa do Brasil, Poder Executivo, Brasília, DF, Brasília, 28 ago. 1996. Disponível em: $<$ http:// www.planalto.gov.br/ccivil_03/DNN/Anterior $\% 20 \mathrm{a} \% 20$ 2000/1996/Dnn4368.htm>. Acesso em: 21 abr. 2012
CANCLINI, N. G. Arte e sociedade. São Paulo: Cortez Editora, 1984.

DIAS, T. L. P.; ROSA, R. S.; DAMASCENO, L. C. P. Aspectos socioeconômicos, percepção ambiental e perspectivas das mulheres marisqueiras da Reserva de Desenvolvimento Sustentável Ponta do Tubarão (Rio Grande do Norte, Brasil). Gaia Scientia, Paraíba, v.1, n.1, p. 25-35, mar. 2007.

DINIZ, M. B.; DINIZ, M. J. T. Arranjo produtivo do artesanato na região metropolitana de Belém: uma caracterização empírica. Novos cadernos NAEA, Pará, v. 10, n. 2, p. 173-208, dez. 2007.

EMBRAPA. Sistema Brasileiro de Classificação de Solos. 2. ed. Brasília: EMBRAPA-SPI, 1999.

FREITAS, A. L. C. Design e artesanato: uma experiência de inserção da metodologia de projeto de produto. 2006. 140 f. Dissertação (Gestão pela Qualidade e Desenvolvimento de Produtos)- Escola de Engenharia, UFMG, Belo Horizonte, 2006.

HALL, P.; BAWA, K. Methods to asses the impact of extraction of non-timber tropical forest products on plant populations. Economic botany, New York, v. 47, n. 3, p. 234-247, Jul. 1993.

HOEFFEL, J. L.; SORRENTINO, M.; MACHADO, M. $\mathrm{K}$. Concepções sobre a natureza e sustentabilidade um estudo sobre percepção ambiental na bacia hidrográfica do Rio Atibainha - Nazaré Paulista/SP. $2^{\circ}$ ENCONTRO DAASSOCIAÇÃO NACIONALDE PÓS-GRADUAÇÃO E PESQUISA EM AMBIENTE E SOCIEDADE. Anais... ANPPAS, 2011. Disponível em: < http://www. anppas.org.br/encontro_anual/encontro2/GT/GT10/ luis_hoffel.pdf $>$. Acesso em: 22 mar. 2011.

IBGE (Instituto Brasileiro de Geografia e Estatística). Censo Populacional 2010. Populações da cidade do Piauí por Bairro. Rio de Janeiro: IBGE, 2010.

JACOMINE, P. K. T. et al. Levantamento exploratório-reconhecimento de solos do Estado do Piauí. Rio de Janeiro: Embrapa/SNLCS/Sudene, 1986. 
JOHANNE, R. E. Integrating traditional ecological Knowledge and management with environmental impact assessment. In: Traditional ecological knowledge: Concepts and cases. Ottawa: Development Research Center, 1993.

MILANO, M. S. Mitos no manejo de unidades de conservação no Brasil, ou a verdadeira ameaça. $2^{\circ}$ CONGRESSO BRASILEIRO DE UNIDADES DE CONSERVAÇÃO, 2000, Campo Grande, Anais... Curitiba: Rede Pró-Unidades de Conservação, 2000.

MINAYO, M. C. S.; SANCHES, O. Quantitativo - qualitativo: oposição ou complementaridade? $\mathrm{Ca}$ derno Saúde Pública, Rio de Janeiro, v. 9, n. 3, p. 239-262, jul./set. 1993.

MINISTÉRIO DE MINAS E ENERGIAS. Mapa de pontos d'água: Município de Parnaiba. Cadastro de Fontes de Abastecimento por Água Subterrânea no estado do Piauí. [S.l], 2003. (1 mapa, color. Escalas variam).

MINISTÉRIO DO TRABALHO E EMPREGO. Seguro desemprego - Pescador Artesanal. Ministério do Trabalho e Emprego (sítio na internet). Disponível em: <http://portal.mte.gov.br/seg_desemp/seguro-desemprego-pescador-artesanal.htm $>$. Acesso em: 9 set. 2012.

NORDI, N. Os catadores do caranguejo-uçá (Ucides cordatus) da Região de Várzea Nova (PB): uma abordagem ecológica e social. 1992. 107 f. Tese (Doutorado em Ecologia e Recursos Naturais), UFSCar, São Carlos, 1992.

RIBEIRO, B. G. Artesanato indígena: para quê, para quem? In: RIBEIRO. B. G. (Org). O papel do artesão na sociedade contemporânea. Rio de Janeiro: FUNARTE, 1984. p.12-26.

SANTOS FILHO, F. S. Composição florística e estrutural da vegetação de restinga do Estado do Piaui. 2009. 124 f. Tese (Doutorado em Botânica) - Centro de Ciências Biológicas, Universidade Federal Rural de Pernambuco, Pernambuco, 2009.
SANTOS, R. L. Desenvolvimento local sustentável: caracterização do APL de artesanato de linha do município de Tobias Barreto - SE. 2007. 135f. Dissertação (Mestrado em Desenvolvimento e Meio Ambiente) - Universidade Federal de Sergipe, São Cristóvão, 2007.

SCHMIDT, I. B. Etnobotânica e ecologia populacional de Syngonanthus nitens: sempre-viva utilizada para artesanato no Jalapão, Tocantins. 2005. 91f. Dissertação (Mestrado em ecologia) - Centro de ciências Biológicas, Universidade de Brasília, Brasília, 2005.

SCHMIDT, I. B.; FIGUEIREDO, I. B.; SCARIOT, A. Ethnobotany and Effects of Harvesting on the Population Ecology of Syngonanthus nitens (Bong.) Ruhland (Eriocaulaceae), a NTFP from Jalapão Region, Central Brazil. Economic Botany, New York, v. 61, n. 1, p. 73-85, Mar. 2007.

SEBRAE (Serviço de Apoio à Pequena Empresa). Estudo setorial do artesanato. Sebrae: Brasília (s/d). Disponível em: <http://www.biblioteca.sebrae.com. br/bds/bds.nsf/E1B356515E8B5D6D8325762500 6D7DA9/\$File/NT00041F56.pdf>. Acesso em: 13 fev, 2012.

SERVETTO, M. La artesania en la zona Andina Argentina: propuestas para el desarrollo. Córdoba: Servicio de Publicaciones de la Universidad de Córdoba, 1998. SINGER, P. Ética prática. São Paulo: Martins Fontes, 1994.

SOTO, A. S. Las artesanias y el diseño. In: NOVELO, V. (coord.) La capacitación de artesanos en México, una revisión. México: Plaza y Valdes, 2003. p.02-10. SOUSA, M. R. S; SOUSA, A. J. Vestígios artesanais na biodiversidade e plasticidade do Buriti. In: II CONGRESSO DE PESQUISA E INOVAÇÃO DA REDE NORTE NORDESTE DE EDUCAÇÃO TECNOLÓGICA., João Pessoa, 2007. Anais... João Pessoa: CEFET, 2007. 
STRANZ, A. et al. Projeto Universidade solidária transmitindo experiências em Educação Ambiental. In: I SIMPÓSIO SUL BRASILEIRO DE EDUCAÇÃO AMBIENTAL; II SIMPÓSIO GAÚCHO DE EDUCAÇÃO AMBIENTALE XIV SEMANAALTO URUGUAI DE MEIO AMBIENTE, 2002, Porto Alegre. Anais... Porto Alegre: EdiFAPES, 2002.

VIEIRA, I. R.; VEROLA, C. F.; LOIOLA, M. I. B. O agro-extrativismo em torno da produção de artesanato de palha de carnaúba (Copernicia prunifera (Miller) H.E.Moore) e o desenvolvimento sustentável local na comunidade Ilha Grande de Santa Isabel, Parnaíba, Piauí. In: VII CONGRESSO BRASILEIRO DE AGROECOLOGIA, 2005, Fortaleza. Anais... Fortaleza, 2011. Disponível em: <http://www.aba-agroecologia.org.br/ojs2/index.php/cad/article/ view/11402/8430>. Acesso em: 5 abr. 2012.

ZAMPIERON, S. L. M.; FAGIONATO, S.; RUFFINO, P. H. P. Ambiente, Representação Social e Percepção. In: Schiel, D. et al. (orgs.). O estudo de bacias hidrográficas: uma estratégia para educação ambiental. 2. ed. São Carlos: RIMA, 2003 . p.21-33. 